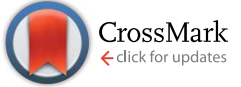

Cite this: Chem. Sci., 2017, 8, 2033

\title{
Expedient synthesis of the heneicosasaccharyl mannose capped arabinomannan of the Mycobacterium tuberculosis cellular envelope by glycosyl carbonate donors $\dagger$
}

\begin{abstract}
Maidul Islam, Ganesh P. Shinde and Srinivas Hotha*
The global incidence of tuberculosis is increasing at an alarming rate, and Mycobacterium tuberculosis (Mtb) is the causative agent for tuberculosis, a disease with high mortality. Lipoarabinomannan (LAM) is one of the major components of the Mtb cellular envelope and is an attractive scaffold for developing anti-tubercular drugs, vaccines and diagnostics. Herein, a highly convergent strategy is developed to synthesize heneicosasaccharyl arabinomannan for the first time. The arabinomannan synthesized in this endeavour has several 1,2-trans or $\alpha$-Araf linkages and three 1,2-cis or $\beta$-Araf linkages end capped with 1,2-trans or $\alpha$-Manp linkages. All the key glycosidations were performed with alkynyl carbonate glycosyl donors under [Au]/[Ag] catalysis conditions, which gave excellent yields and stereoselectivity even for the reactions between complex and branched oligosaccharides. The resultant allyl oligosaccharide was globally deprotected to obtain the heneicosasaccharyl arabinomannan as a propyl glycoside. In summary, heneicosasaccharyl mannose capped arabinomannan synthesis was achieved in 56 steps with $0.016 \%$ overall yield
\end{abstract}

Received 2nd November 2016
Accepted 15th November 2016

DOI: $10.1039 / \mathrm{c} 6 \mathrm{sc} 04866 \mathrm{~h}$

www.rsc.org/chemicalscience

\section{Introduction}

The world-wide resurgence of mycobacterial infections coupled with the emergence of multi- and extreme drug resistance have placed tuberculosis (TB) as a major public health concern. ${ }^{1-3}$ The only available protection against tuberculosis is the BCG vaccine; however, multi-centered clinical trials demonstrated variable efficacy. ${ }^{4}$ Tuberculosis infections are caused by Mycobacterium tuberculosis (Mtb), which has a thick waxy cell wall making it impervious to drugs., ${ }^{5,6}$ As a consequence, patients suffering from TB are prescribed a long regimen of multiple drugs. Therefore, TB is an ever growing challenge, and novel strategies to diagnose, control or eradicate it are in great demand.

The chemical structure of the waxy cellular envelope has been identified as a unique glycocalyx comprising mycolic acids, Ara $f$, Gal $f$, Man $p$, Rhap and inositols. ${ }^{7-10}+$ Further investigations revealed that the glycocalyx contains trehalose lipids, lipoarabinomannan (LAM), arabinogalactan (AG) and peptidoglycan. ${ }^{7-10}$ Of these, the structure of LAM was noticed to have a key C-3 branched arabinan domain with many $\alpha-1 \rightarrow 5$-linked

Department of Chemistry, Indian Institute of Science Education and Research, Pune411 008, India. E-mail: s.hotha@iiserpune.ac.in

$\dagger$ Electronic supplementary information (ESI) available: Experimental procedures, compound characterization data and spectral charts. See DOI: $10.1039 / \mathrm{c} 6 \mathrm{sc} 04866 \mathrm{~h}$
D-Arafs, and a few $\beta$-1 $\rightarrow$ 2-linked D-Arafs capped with $\alpha-1 \rightarrow 2$ linked D-Manps at the non-reducing end. ${ }^{7-10,13}$ It has been well established that mannose capped LAM (ManLAM) is prevalent in more pathogenic mycobacterial species such as $M$. tuberculosis, M. leprae, M. bovis. ${ }^{11-13}$ ManLAM has been shown to inhibit the production of tumor necrosis factor- $\alpha$ (TNF- $\alpha$ ) and interleukin-12 (IL-12) by human dendritic cells and macrophages in vitro to modulate $M$. tuberculosis induced macrophage apoptosis. ${ }^{\mathbf{1 4 , 1 5}}$ Quite recently, a rapid point of care diagnostic kit was developed exploiting the antigenic properties of ManLAM. ${ }^{16-18}$ In another study LAM was investigated as a candidate vaccine for mycobacterial diseases. Thus, the non-reducing end portion of LAM is beneficial to various immunological studies, diagnostics and the development of carbohydrate-based tuberculosis vaccines.

Owing to the significance of ManLAM, the synthesis of ManLAM and arabinan fragments has been attempted over the last two decades. ${ }^{19-27,44}$ A recent investigation by Guo's group verified the synthetic and immunological potential of protein conjugated ManLAM fragments. ${ }^{28}$ However, far too little attention has been paid to synthesizing the large oligomers in ManLAM. The main aim of the current research has therefore been to synthesize naturally occurring large oligosaccharide portions of ManLAM such as arabinomannan 1 (Fig. 1) to facilitate vaccine and diagnostic development. 


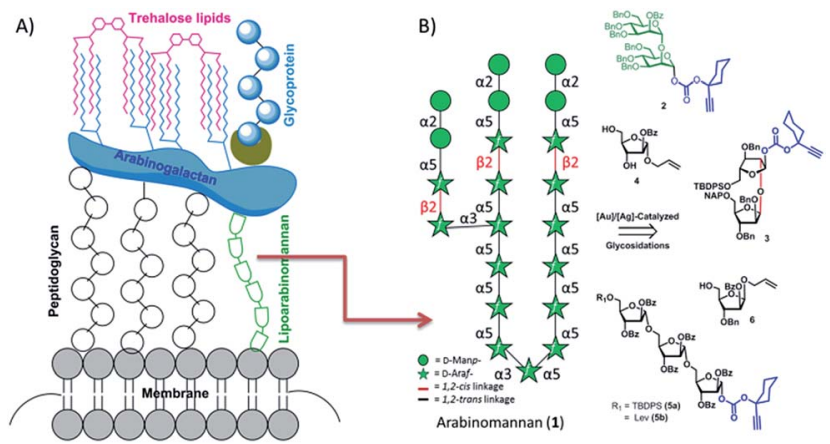

Fig. 1 Cartoon representation of the Mycobacterium tuberculosis cell wall (A) and the retrosynthesis of heneicosasaccharyl mannose capped arabinan (B).

\section{Results and discussion}

The arabinomannan moiety (1) offers many complexities and challenges in its synthesis in terms of the type and number of linkages and the asymmetric branching.Careful retrosynthetic disconnection revealed that the target molecule, as a propyl glycoside, can be synthesized conveniently using two disaccharides $(2,3)$, two monosaccharides $(\mathbf{4}, \mathbf{6})$ and a trisaccharide (5) (Fig. 1). Apart from their continued interest, ${ }^{29-34}$ alkynyl carbonate donors are chosen as they undergo catalytic activation in the presence of gold and silver salts, and are therefore fast and high yielding. ${ }^{35}$ The neighboring group or reciprocal donor acceptor selectivity assisted synthesis of 1,2-trans or $\alpha$-linkages and stereoelectronics guided synthesis of 1,2-cis or $\beta$-Araf $f$ was envisioned. ${ }^{36}$ An allyl moiety was strategically placed at the anomeric position since it is stable and orthogonal to -OTBDPS, -OBz, and -ONAP protecting groups and can be converted to a hemiacetal en route to glycosyl donor preparation. In addition, an allyl moiety can also be exploited for the conjugation of proteins and biomolecules. ${ }^{37-40}$

Our synthetic endeavour started with the preparation of a triarabinofuranosyl carbonate donor (Scheme 1). Easily accessible allyl arabinofuranoside $7^{41}$ was converted into fully protected compound 8 by first protecting the $\mathrm{C}-5-\mathrm{OH}$ as a silyl ether using TBDPS-Cl, followed by the protection of the remaining hydroxyls as benzoates with $\mathrm{BzCl} / \mathrm{py} / \mathrm{DMAP}$. Compound 8 serves as a common building block for the synthesis of both glycosyl donors and acceptors. Accordingly, compound $\mathbf{8}$ has been split into two portions and one portion was converted into the glycosyl acceptor 9 by treatment with HF. py in THF whereas the second portion was converted into hemiacetal 10 using $\mathrm{PdCl}_{2}$; subsequently, this was transformed to glycosyl donor $\mathbf{1 2}$ by reacting it with easily available ethynyl cyclohexyl(4-nitrophenyl)carbonate 11 (Scheme 1).

The first $[\mathrm{Au}] /[\mathrm{Ag}]$-glycosidation between acceptor $\mathbf{9}$ and donor $\mathbf{1 2}$ was successfully performed to afford disaccharide $\mathbf{1 3}$ in excellent yield. ${ }^{35}$ In continuation, a lone silyl ether was deprotected under HF.py conditions to afford acceptor $\mathbf{1 4}$ which was glycosylated again with the glycosyl donor $\mathbf{1 2}$ under gold/silver catalytic conditions to obtain trisaccharide 15a as an

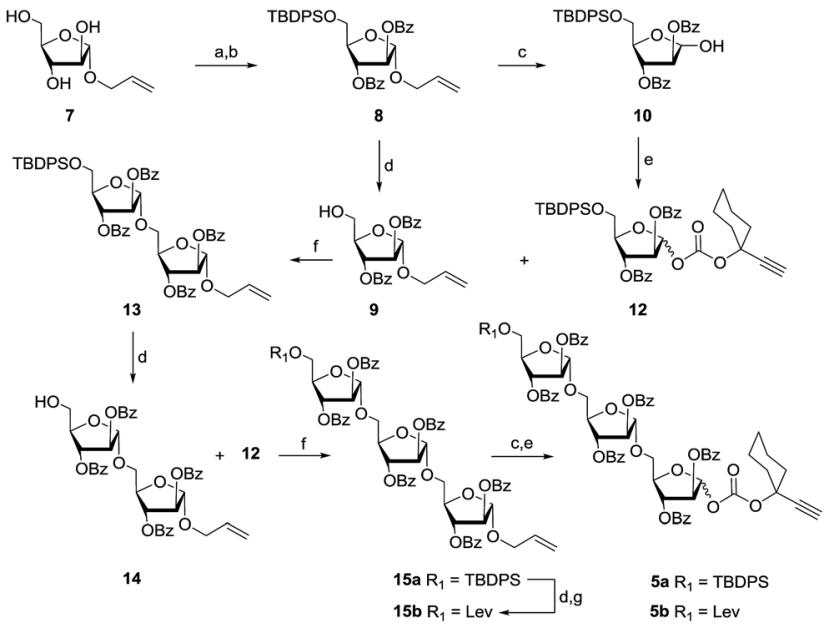

Scheme 1 Reagents: (a) TBDPS-Cl, Im., DMF, $0{ }^{\circ} \mathrm{C}, 1 \mathrm{~h}, 82 \%$; (b) $\mathrm{BzCl}$, pyridine, DMAP, $0-25{ }^{\circ} \mathrm{C}, 5 \mathrm{~h}, 93 \%$; (c) $\mathrm{PdCl}_{2}, \mathrm{CH}_{2} \mathrm{Cl}_{2}-\mathrm{MeOH}(1: 4)$, $25^{\circ} \mathrm{C}, 4 \mathrm{~h}, 85 \%$; (d) HF. py, pyridine, $0-25^{\circ} \mathrm{C}, 5 \mathrm{~h}, 93 \%$ for $9,91 \%$ for 14 , and $90 \%$ for $15 \mathrm{~b}$; (e) 1-ethynyl cyclohexyl(4-nitrophenyl)carbonate (11), $\mathrm{CH}_{2} \mathrm{Cl}_{2}, \mathrm{DMAP}, 0-25^{\circ} \mathrm{C}, 3 \mathrm{~h}, 85 \%$ for $12,83 \%$ for $5 \mathrm{a}$ and $85 \%$ for $5 \mathrm{~b}$ over two steps; (f) 8 mol\% chloro[tris(2,4-di-tert-butylphenyl)phosphite] gold, $8 \mathrm{~mol} \% \mathrm{AgOTf}, \mathrm{CH}_{2} \mathrm{Cl}_{2}, 4 \AA \mathrm{MS}$ powder, $25^{\circ} \mathrm{C}, 15 \mathrm{~min}, 95 \%$ for 13 and $92 \%$ for $15 \mathrm{a}$; (g) levulinic acid, DIC, DMAP, $\mathrm{CH}_{2} \mathrm{Cl}_{2}, 0-25^{\circ} \mathrm{C}$, 2 h, $95 \%$

allyl glycoside. Cleavage of the silyl ether and protection as a levulinoate resulted in the other required trisaccharide $\mathbf{1 5 b}$. Trisaccharides 15a and $\mathbf{1 5 b}$ were respectively converted easily into the triarabinofuranosyl carbonate donors $\mathbf{5 a}$ and $\mathbf{5 b}$ (Scheme 1). ${ }^{46}$

In parallel, allyl mannopyranoside $\mathbf{1 7}$ was synthesized from known mannopyranosyl 1,2-orthoester $16^{27}$ under acidic conditions. Subsequently, allyl glycoside 17 was split into two portions and one part was subjected to saponification under Zemplén conditions ${ }^{42}$ to afford the acceptor 18 , and the other part was converted into the glycosyl donor 19 in two easy steps. The gold/silver assisted glycosidation between the donor 19 and the acceptor 18 went uneventfully affording $93 \%$ of the disaccharide 20 which was subsequently converted into the other required building block 2 in two steps (Scheme 2). ${ }^{46}$

The synthesis of the next important 1,2-cis disaccharide 3 was initiated with the saponification of compound $\mathbf{8}$ under Zemplén conditions $(\mathrm{NaOMe} / \mathrm{MeOH})$; the subsequent conversion of particular groups to benzyl ethers afforded compound 21. Moving on, the cleavage of the silyl ether using HF-py and protection of the resulting hydroxyl group as a NAP ether went effortlessly by employing NAP-Br to afford NAP-protected allyl glycoside 22. Hydrolysis of the allyl glycoside using $\mathrm{PdCl}_{2}$ and its conversion to the corresponding donor 23 was achieved in very high yield. In parallel, compound $\mathbf{2 4}$ was protected as benzyl ether 25 using $\mathrm{NaH} / \mathrm{BnBr} / \mathrm{DMF}$ and the opening of the isopropylidene moiety was performed in the presence of allyl alcohol under acidic conditions to afford an $\alpha, \beta$-mixture of glycosides.

Earlier studies from our group demonstrated that the reciprocal donor acceptor selectivity depends on the reactivity of 


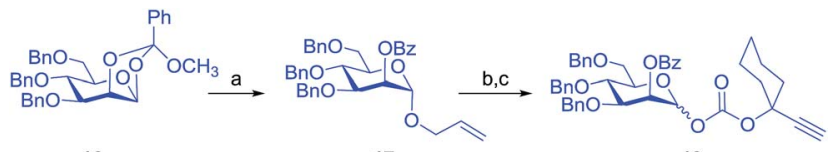

16
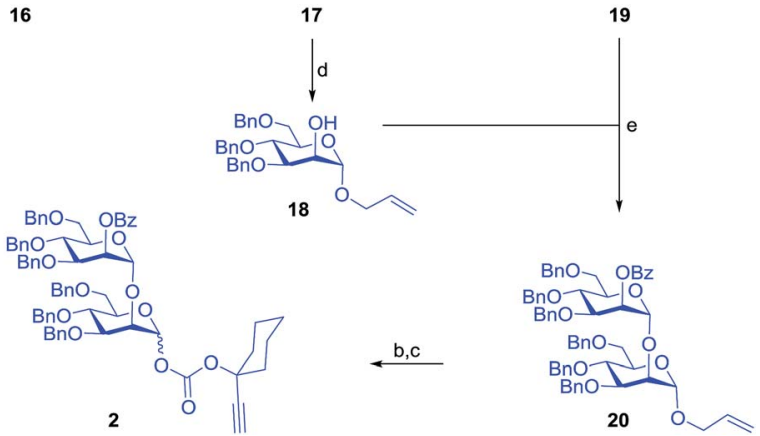

Scheme 2 Reagents: (a) PTSA (0.2 eq.), allyl alcohol, $\mathrm{CH}_{2} \mathrm{Cl}_{2}, 4 \AA$ MS powder, $25^{\circ} \mathrm{C}, 1 \mathrm{~h}, 86 \%$; (b) $\mathrm{PdCl}_{2}, \mathrm{CH}_{2} \mathrm{Cl}_{2}-\mathrm{MeOH}(1: 4), 25^{\circ} \mathrm{C}, 4 \mathrm{~h}$, $90 \%$ towards 19; (c) $11, \mathrm{CH}_{2} \mathrm{Cl}_{2}$, DMAP, $0-25{ }^{\circ} \mathrm{C}, 3 \mathrm{~h}, 78 \%$ for 19 and $83 \%$ for 2 over two steps; (d) $\mathrm{NaOMe}, \mathrm{MeOH}, 25{ }^{\circ} \mathrm{C}, 1 \mathrm{~h}, 94 \%$; (e) $8 \mathrm{~mol} \%$ chloro[tris(2,4-di-tert-butylphenyl)phosphite] gold, $8 \mathrm{~mol} \%$ AgOTf, $\mathrm{CH}_{2} \mathrm{Cl}_{2}, 4 \AA \mathrm{MS}$ powder, $25^{\circ} \mathrm{C}, 15 \mathrm{~min}, 93 \%$.

the nucleophile and the stereoelectronics around the C-2 position of the glycosyl acceptor. ${ }^{36}$ Accordingly, the allyl glycosides were separated by flash silica gel column chromatography and this isolated the required 1,2-cis disposed allyl glycoside 26 . Glycosyl donor 23 and acceptor 26 were subjected to [Au]/[Ag]catalysed glycosidation conditions to afford the 1,2-cis or $\beta$-disaccharide 27 in $92 \%$ yield as a single diastereomer further verifying our earlier results. ${ }^{36,46}$ Subsequently, the disaccharide 27 was converted into the required glycosyl donor 3 in two steps viz. the Pd-catalysed hydrolysis of the allyl glycoside to a hemiacetal followed by its conversion to the ethynylcyclohexyl carbonate by treating it with compound $\mathbf{1 1}$ and DMAP. Orthogonally cleavable TBDPS and NAP ethers were selected for installing the mannopyranosyl disaccharide at a later stage (Scheme 3).

Synthesis of another monosaccharide 4 commenced with the saponification of easily accessible compound $28{ }^{43}$ under Zemplén conditions ( $\mathrm{NaOMe} / \mathrm{MeOH})$ followed by its conversion to disilyl ether 29 using TBDPSCl/Im./DMAP resulting in $81 \%$ yield over two steps. Acid mediated opening of the 1,2orthoester in the presence of an allyl alcohol afforded the allyl glycoside in $80 \%$ yield. Cleavage of the silyl ethers was achieved using HF· py to afford the allyl glycoside 4, and the resulting C-5 hydroxyl group was protected as its silyl ether to afford the glycosyl acceptor 31 .

Synthesis of enough quantities of all of the identified major partners drove the assembly of ManLAM. Accordingly, the glycosyl acceptor $\mathbf{3 1}$ and the glycosyl donor $\mathbf{5 b}$ were first glycosylated under gold-silver catalysed glycosidation conditions to afford the tetrasaccharide 32 in excellent yield. ${ }^{46}$ Deprotection of the silyl ether using HF py to obtain 33 and subsequent treatment with glycosyl donor 5a, with $8 \mathrm{~mol} \%$ each of AgOTf and a gold-phosphite catalyst in $\mathrm{CH}_{2} \mathrm{Cl}_{2}$, afforded the required heptasaccharide 34 in $92 \%$ yield (Scheme 4$)$.

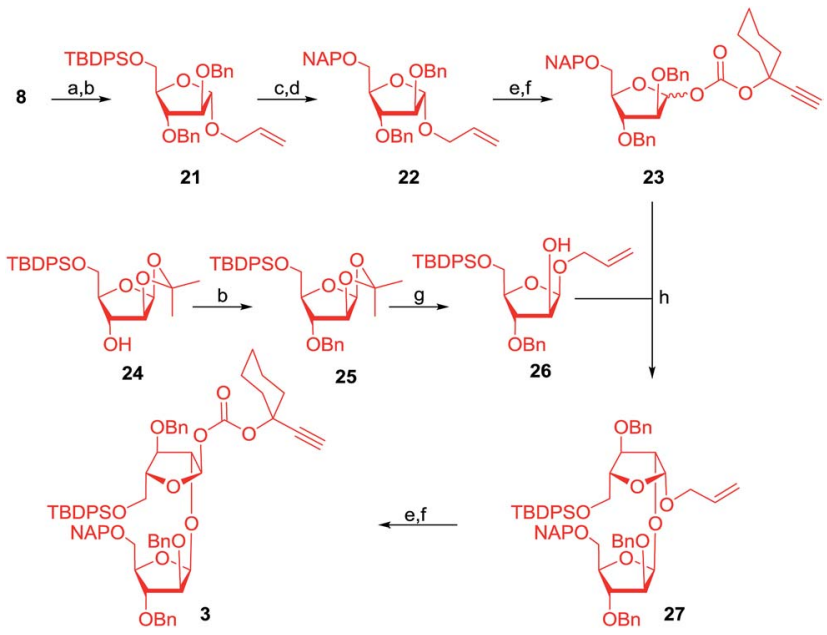

Scheme 3 Reagents: (a) $\mathrm{NaOMe}, \mathrm{MeOH}, 25^{\circ} \mathrm{C}, 1 \mathrm{~h}, 90 \%$; (b) $\mathrm{NaH}$, $\mathrm{BnBr}, \mathrm{TBAl}, \mathrm{DMF}, 0-25{ }^{\circ} \mathrm{C}, 1 \mathrm{~h}, 91 \%$ for 21 and $93 \%$ for 25; (c) HF.py, pyridine, $0-25^{\circ} \mathrm{C}, 5 \mathrm{~h}, 92 \%$; (d) $\mathrm{NaH}, \mathrm{NAPBr}, \mathrm{TBAl}, \mathrm{DMF}, 0-25^{\circ} \mathrm{C}, 2 \mathrm{~h}$, 90\%; (e) $\mathrm{PdCl}_{2}, \mathrm{CH}_{2} \mathrm{Cl}_{2}-\mathrm{MeOH}(1: 4), 25^{\circ} \mathrm{C}, 4 \mathrm{~h}$; (f) 11, DMAP, $\mathrm{CH}_{2} \mathrm{Cl}_{2}$, $0-25{ }^{\circ} \mathrm{C}, 3 \mathrm{~h}, 82 \%$ for 23 and $78 \%$ for 3 over two steps; (g) PTSA (0.2 eq.), allyl alcohol, $\mathrm{CH}_{2} \mathrm{Cl}_{2}, 50{ }^{\circ} \mathrm{C}, 2 \mathrm{~h}, 45 \%$; (h) 8 mol\% chloro [tris(2,4-di-tert-butylphenyl)phosphite] gold, $8 \mathrm{~mol} \% \mathrm{AgOTf}, \mathrm{CH}_{2} \mathrm{Cl}_{2}$, $4 \AA$ MS powder, $-78^{\circ} \mathrm{C}, 5 \mathrm{~h}, 92 \%$.

Protection of the C-2 hydroxyl group of compound 26 as a benzoate followed by the unblocking of the C-5 hydroxyl group by the addition of $\mathrm{HF}$-py resulted in the glycosyl acceptor 6. Subsequently, glycosyl acceptor 6 was treated with the donor 3 under gold-silver catalysis conditions to afford the required trisaccharide $35 .{ }^{35}$ The diastereoselectivity of the reaction was noticed to be temperature dependent. The

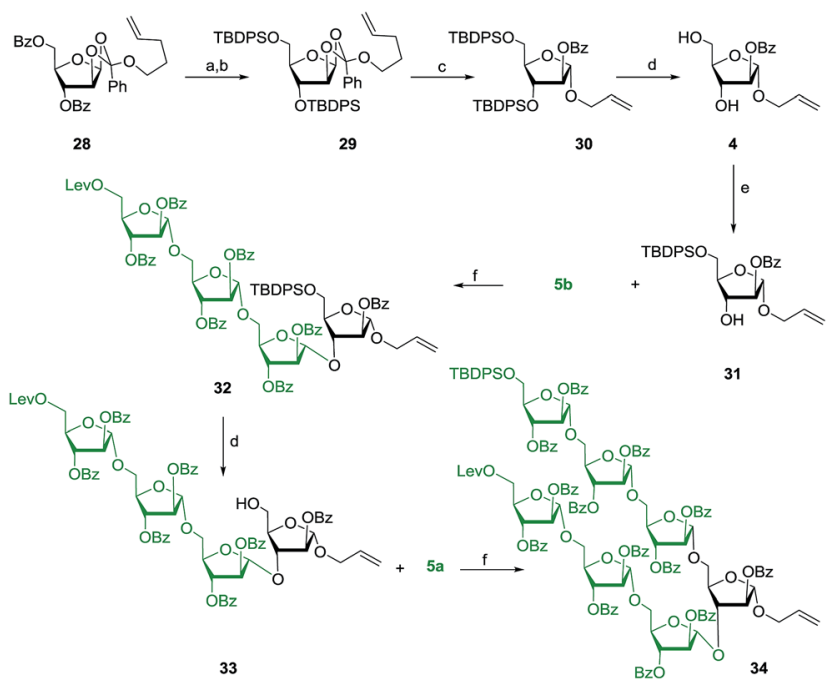

Scheme 4 Reagents: (a) NaOMe, MeOH, $25^{\circ} \mathrm{C}, 1 \mathrm{~h}, 95 \%$; (b) TBDPS$\mathrm{Cl}$ (2.5 eq.), Im., DMF, $0-25^{\circ} \mathrm{C}, 2 \mathrm{~h}, 85 \%$; (c) PTSA ( 0.2 eq.), excess allyl alcohol, $\mathrm{CH}_{2} \mathrm{Cl}_{2}, 4 \AA \mathrm{MS}$ powder, $25^{\circ} \mathrm{C}, 1 \mathrm{~h}, 80 \%$; (d) HF.py, pyridine, 0-25 ${ }^{\circ} \mathrm{C}, 6 \mathrm{~h}, 90 \%$ for 4 and $90 \%$ for 33 ; (e) TBDPS-Cl, Im., DMF, $0{ }^{\circ} \mathrm{C}$, $1 \mathrm{~h}, 80 \%$; (f) 8 mol\% chloro[tris(2,4-di-tert-butylphenyl)phosphite] gold, 8 mol\% AgOTf, $\mathrm{CH}_{2} \mathrm{Cl}_{2}, 4 \AA \mathrm{MS}$ powder, $25^{\circ} \mathrm{C}, 20 \mathrm{~min}, 95 \%$ for 32 and $92 \%$ for 34 . 
diastereomeric ratio swung in favour of the desired $\alpha$-isomer as the temperature of the reaction was lowered. The best $8: 1$ ratio $(\alpha: \beta)$ in favour of the desired isomer with an overall yield of $90 \%$ (which translates to $80 \%$ of the trisaccharide 35 ) was accomplished at $-78{ }^{\circ} \mathrm{C}$ and that might be due to the presence of a bulky 5-O-TBDPS moiety (Scheme 5). ${ }^{36}$ The naphthyl moiety was deprotected using DDQ and $\mathrm{CH}_{2} \mathrm{Cl}_{2}-\mathrm{MeOH}(1: 4)$ at $25{ }^{\circ} \mathrm{C}$ to obtain the acceptor 36 which was further treated with the mannopyranosyl donor 2 to obtain the pentasaccharide 37 in $76 \%$ yield. A two step conversion transformed allyl glycoside 37 into the glycosyl donor $\mathbf{3 8}$ in $75 \%$ yield (Scheme 5).

A glycosidation reaction between donor 3 and acceptor 4 afforded another pentasaccharide 39 as an allyl glycoside in $77 \%$ yield in the presence of $8 \mathrm{~mol} \%$ each of $\mathrm{Au}$-phosphite and AgOTf. The stereochemical outcome of glycosidation was noticed to be temperature dependent. Careful analysis of the glycosidation revealed that the mixture of glycosides $(\alpha: \beta=$ $8: 1$ ) results from the $\mathrm{C}-5$ position of the acceptor, but not from the C-3 position of acceptor 4 .

Gratifyingly, the mixture of pentasaccharides could be separated using flash silica gel column chromatography to obtain $77 \%$ of the desired pentasaccharide $39 .{ }^{15}$ Deprotection of the NAP-ether was achieved to afford the diol 40 which upon treatment with mannopyranosyl donor 2 gave nonasaccharide 41. In the ${ }^{13} \mathrm{C}$ NMR spectrum of the nonasaccharide 41, resonances due to nine anomeric carbons were noticed at $\delta=98.6$, 98.8, 99.7, 99.8, 100.0, 100.5, 105.1, 105.5, and $106.8 \mathrm{ppm}$. Subsequently, the nonasaccharide was converted into the corresponding carbonate glycosyl donor $\mathbf{4 2}$ in $76 \%$ yield (Scheme 6).

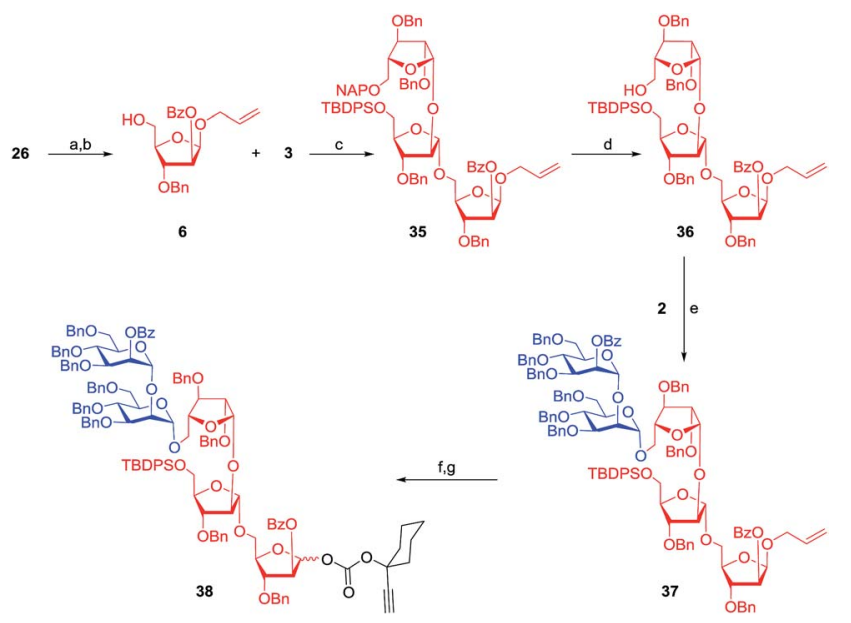

Scheme 5 Reagents: (a) $\mathrm{BzCl}$, pyridine, DMAP, $0-25{ }^{\circ} \mathrm{C}, 5 \mathrm{~h}, 93 \%$; (b) HF-py, pyridine, $0-25{ }^{\circ} \mathrm{C}, 5 \mathrm{~h}, 94 \%$; (c) $8 \mathrm{~mol} \%$ chloro[tris(2,4-ditert-butylphenyl)phosphite] gold, 8 mol\% AgOTf, $\mathrm{CH}_{2} \mathrm{Cl}_{2}, 4 \AA \mathrm{MS}$ powder, $-78{ }^{\circ} \mathrm{C}, 5 \mathrm{~h}, 80 \%$ (overall yield $90 \%$ with $\alpha: \beta=8: 1$ ); (d) $\mathrm{DDQ}, \mathrm{CH}_{2} \mathrm{Cl}_{2}-\mathrm{MeOH}$ (1: 4), $25{ }^{\circ} \mathrm{C}, 4 \mathrm{~h}, 82 \%$; (e) 8 mol\% chloro [tris(2,4-di-tert-butylphenyl)phosphite] gold, 8 mol\% AgOTf, $\mathrm{CH}_{2} \mathrm{Cl}_{2}, 4 \AA \mathrm{MS}$ powder, $25{ }^{\circ} \mathrm{C}, 15 \mathrm{~min}, 76 \%$; (f) $\mathrm{PdCl}_{2}, \mathrm{CH}_{2} \mathrm{Cl}_{2}-$ $\mathrm{MeOH}(1: 4), 25^{\circ} \mathrm{C}, 4 \mathrm{~h}$; (g) $11, \mathrm{DMAP}, \mathrm{CH}_{2} \mathrm{Cl}_{2}, 0-25^{\circ} \mathrm{C}, 3 \mathrm{~h}, 75 \%$ over two steps.
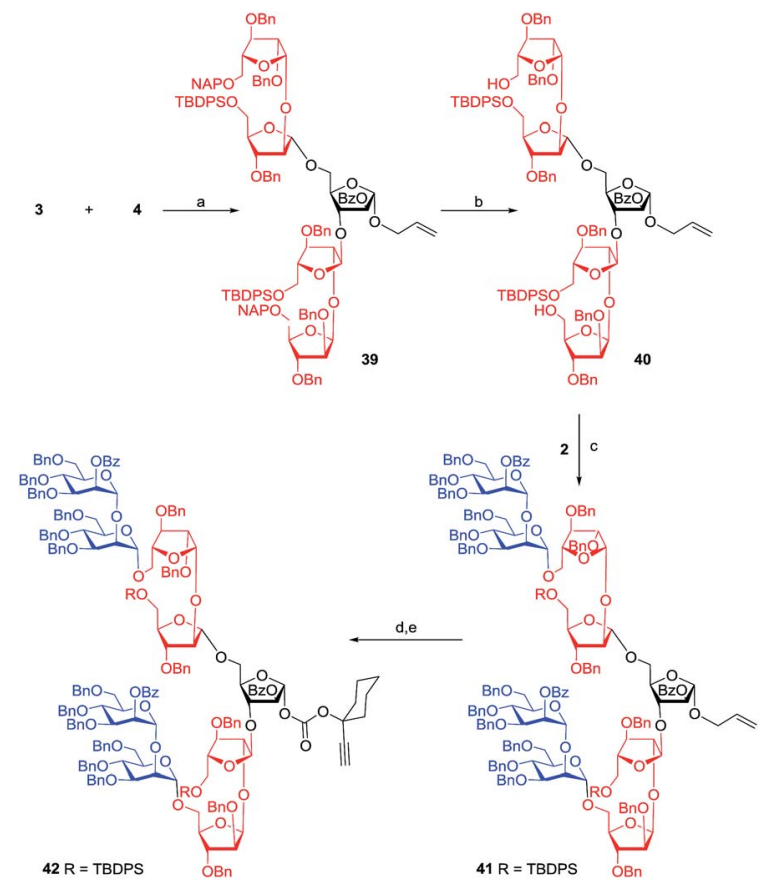

Scheme 6 Reagents: (a) 8 mol\% chloro[tris(2,4-di-tert-butylphenyl) phosphite] gold, $8 \mathrm{~mol} \% \mathrm{AgOTf}, \mathrm{CH}_{2} \mathrm{Cl}_{2}, 4 \AA \mathrm{MS}$ powder, $-78{ }^{\circ} \mathrm{C}, 5 \mathrm{~h}$, $77 \%$ (overall yield $87 \%$ with $\alpha: \beta=8: 1$ ); (b) $\mathrm{DDQ}, \mathrm{CH}_{2} \mathrm{Cl}_{2}-\mathrm{MeOH}$ (1: 4), $25^{\circ} \mathrm{C}, 4 \mathrm{~h}, 75 \%$; (c) 8 mol\% chloro[tris(2,4-di-tert-butylphenyl) phosphite] gold, $8 \mathrm{~mol} \% \mathrm{AgOTf}, \mathrm{CH}_{2} \mathrm{Cl}_{2}, 4 \AA \mathrm{MS}$ powder, $25^{\circ} \mathrm{C}, 15 \mathrm{~min}$, $60 \%$; (d) $\mathrm{PdCl}, \mathrm{CH}_{2} \mathrm{Cl}_{2}-\mathrm{MeOH}(1: 4), 25^{\circ} \mathrm{C}, 4 \mathrm{~h}$; (e) 11, DMAP, $\mathrm{CH}_{2} \mathrm{Cl}_{2}$, $0-25{ }^{\circ} \mathrm{C}, 3 \mathrm{~h}, 76 \%$ over two steps.

The final assembly of heneicosaarabinomannan 1 started with the deprotection of silyl ether $\mathbf{3 4}$ using HF.py to afford alcohol 43 which was glycosylated with donor 38 using $8 \mathrm{~mol} \%$ each of gold-phosphite and AgOTf to afford dodecassacharide 44 in $85 \%$ yield. Twelve characteristic resonances due to anomeric carbons were noticed in the anomeric region $(\delta=$ 98.7-106.2 ppm) of the NMR spectrum. ${ }^{46}$ The lone levulinoate was hydrolysed with hydrazine acetate in THF-MeOH to afford the required glycosyl acceptor $\mathbf{4 5 .}^{45}$ The final glycosidation between acceptor 45, containing twelve saccharide residues, and the glycosyl donor 42, containing nine carbohydrate residues, was performed in the presence of $8 \mathrm{~mol} \%$ each of $\mathrm{Au}-$ phosphite and AgOTf resulting in the formation of the fully protected heneicosaarabinomannan 46 in $80 \%$ yield. In the ${ }^{13} \mathrm{C}$ NMR spectrum of arabinomannan 46, resonances due to the anomeric carbons were noticed as two sets centred on $\delta=98.8-$ $100.7 \mathrm{ppm}$ and $\delta=105.1-107.3 \mathrm{ppm}$ for 21-anomeric carbons (Scheme 7). ${ }^{4}$ Oligosaccharide $\mathbf{4 6}$ can be subjected to a variety of reactions in order to attach biomolecules; however, the global deprotection of compound $\mathbf{4 6}$ was considered to show that the molecule is stable under the conditions employed for the cleavage of protecting groups. Cleavage of the three silyl ethers was carried out using the HF·py, Zemplén debenzoylation resulted in the saponification of eighteen benzoates and the final hydrogenolysis with $\mathrm{Pd}(\mathrm{OH})_{2} / \mathrm{H}_{2}$ caused the deprotection of twenty eight benzyl ethers and the reduction of the olefin as 


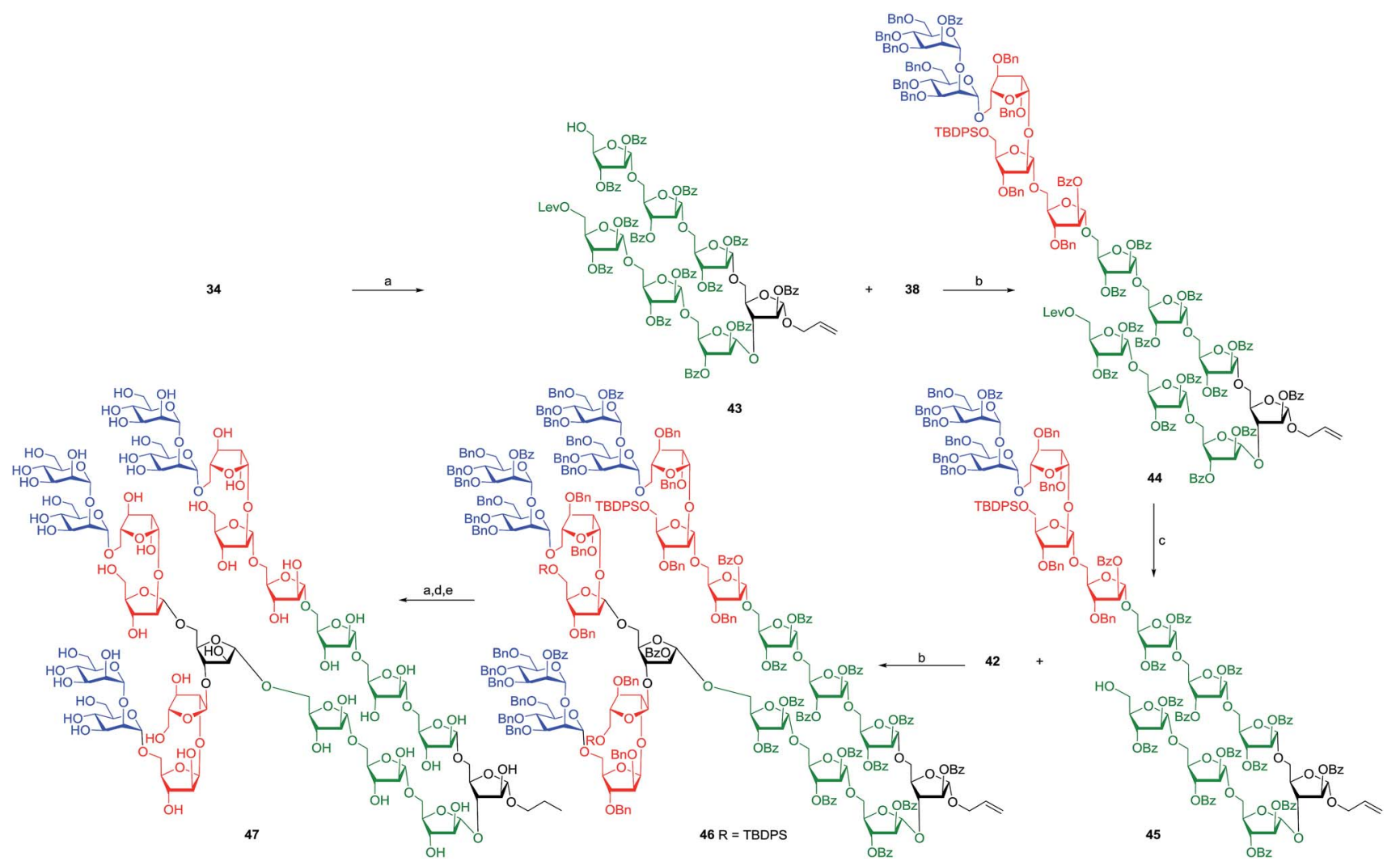

Scheme 7 Reagents: (a) HF.py, pyridine, $0-25^{\circ} \mathrm{C}, 5 \mathrm{~h}, 83 \%$ for 43 and $80 \%$ for 47 ; (b) 8 mol\% chloro[tris(2,4-di-tert-butylphenyl)phosphite] gold, $8 \mathrm{~mol} \% \mathrm{AgOTf}, \mathrm{CH}_{2} \mathrm{Cl}_{2}, 4 \AA \mathrm{MS}$ powder, $25^{\circ} \mathrm{C}, 30 \mathrm{~min}, 85 \%$ for 44 and $80 \%$ for 46 ; (c) hydrazine acetate, $\mathrm{THF}-\mathrm{MeOH}(4: 1), 25{ }^{\circ} \mathrm{C}, 45 \mathrm{~min}$, $80 \%$; (d) $\mathrm{NaOMe}, \mathrm{MeOH}, 25{ }^{\circ} \mathrm{C}, 15 \mathrm{~h}, 87 \%$; (e) $\mathrm{Pd}(\mathrm{OH})_{2}, \mathrm{CH}_{3} \mathrm{OH}-\mathrm{THF}-\mathrm{H}_{2} \mathrm{O}(4: 3: 3), \mathrm{H}_{2}, 36$ h, $78 \%$.

well affording the heneicosaarabinomannan (47) as its propyl glycoside.

\section{Conclusions}

In summary, the execution of this highly convergent and modular strategy has led to the first synthesis of a branched, hybrid and complex arabinomannan (containing 15-Araf and 6-Manp-residues) from the Mycobacterium tuberculosis cell wall in sufficient amounts for biological explorations with an overall yield of $0.016 \%$. Stable alkynyl carbonate glycosyl donors are shown to be versatile glycosyl donors for the synthesis of large oligosaccharides. $[\mathrm{Au}] /[\mathrm{Ag}]-$ catalytic conditions were employed for all the key glycosylations. 1,2-cis Araf and some 1,2-trans Araf linkages were installed taking advantage of reciprocal donor-acceptor selectivity. Taken together, the synthesis uses stable reactants and catalytic quantities of noble metal salts; therefore, it is experimentally less demanding and operationally convenient.

\section{Acknowledgements}

MI and GPS acknowledge a fellowship from CSIR-UGC-NET. The authors thank financial assistance from DST-SERB-New Delhi [SB/OC/CB-03/2014]. The authors thank DST-FIST funds for the use of the high field NMR facility at IISER Pune.

\section{Notes and references}

I Araf means arabinofuranose; Man $p$ means mannospyranose, Im. means imidazole, DMAP means $4-N, N^{\prime}$-dimethylaminopyridine, THF means tetrahydrofuran, and 4 Å MS means 4 Å molecular sieves.

1 Global Tuberculosis Report, http://apps.who.int/iris/bitstream/ 10665/191102/1/9789241565059_eng.pdf?ua=1, 2015.

2 R. M. Coker, Trop. Med. Int. Health, 2004, 9, 25.

3 M. M. Wade and Y. Zhang, Front. Biosci., 2004, 9, 975.

4 G. Källenius, A. Pawlowski, B. Hamasur and S. V. Svenson, Trends Microbiol., 2008, 16, 456.

$5 \mathrm{X}$. Hong and A. J. Hopfinger, Biomacromolecules, 2004, 5, 1066.

6 J. Liu, C. E. Barry III, G. S. Besra and H. Nikaido, J. Biol. Chem., 1996, 271, 29545.

7 G. S. Besra, K.-H. Khoo, M. R. McNeil, A. Dell, H. R. Morris and P. J. Brennan, Biochemistry, 1995, 34, 4257.

8 P. J. Brennan and H. Nikaido, Annu. Rev. Biochem., 1995, 64, 29.

9 A. Lee, S. W. Wu, M. S. Scherman, J. B. Torrelles, D. Chatterjee, M. R. McNeil and K.-H. Khoo, Biochemistry, 2006, 45, 15817.

10 G. S. Besra and D. Chatterjee, in Tuberculosis: Pathogenesis, Protection and Control, ed. B. R. Bloom, American Society, Microbiology Press, Washington, DC, 1994, pp. 285-306. 
11 J. B. Torrelles, P. A. Sieling, N. Zhang, M. A. Keen, M. R. McNeil, J. T. Belisle, R. L. Modlin, P. J. Brennan and D. Chatterjee, Glycobiology, 2012, 22, 1118.

12 D. Kaur, M. E. Guerin, H. Skovierová, P. J. Brennan and M. Jackson, Adv. Appl. Microbiol., 2009, 69, 23.

13 A. K. Mishra, N. N. Driessen, B. J. Appelmelk and G. S. Besra, FEMS Microbiol. Rev., 2011, 35, 1126.

14 Y. Guérardel, E. Maes, V. Briken, F. Chirat, Y. Leroy, C. Locht, G. Strecker and L. Kremer, J. Biol. Chem., 2003, 278, 36637.

15 M. Gilleron, N. Himoudi, O. Adam, P. Costant, A. Venisse, M. Rivière and G. Puzo, J. Biol. Chem., 1997, 272, 117.

16 K. Dheda, M. Ruhwald, G. Theron, J. Peter and W. C. Yam, Respirology, 2013, 18, 217.

17 S. D. Lawn, A. D. Kerkhoff, M. Vogt and R. Wood, Lancet Infect. Dis., 2012, 12, 201.

18 S. D. Law, BMC Infect. Dis., 2012, 12, 103.

19 K. N. Jayaprakash, J. Lu and B. Fraser-Reid, Angew. Chem., Int. Ed., 2005, 44, 5894.

20 J. Lu and B. Fraser-Reid, Chem. Commun., 2005, 862.

21 B. Fraser-Reid, J. Lu, K. N. Jayaprakash and J. C. Lopez, Tetrahedron: Asymmetry, 2006, 17, 2449.

22 N. M. Podvanyy, P. I. Abronina, K. G. Fedina, N. N. Kondakov, I. Zinin, A. O. Chizhov, V. I. Torgov, V. V. Kachala and L. O. Kononov, Russ. Chem. Bull., 2015, 64, 1149.

23 K. Sahloul and T. L. Lowary, J. Org. Chem., 2015, 80, 11417. 24 J. Gao, G. Liao, L. Wang and Z. Guo, Org. Lett., 2014, 16, 988. 25 B. Fraser-Reid, S. R. Chaudhuri, K. N. Jayaprakash, J. Lu and C. V. S. Ramamurty, J. Org. Chem., 2008, 73, 9732.

26 C. E. Chan, S. Gotze, G. T. Seah, P. H. Seeberger, N. Tukvadze, M. R. Wenk, B. J. Hanson and P. A. MacAry, Sci. Rep., 2015, 5, 10281.

27 A. Hölemann, B. L. Stocker and P. H. Seeberger, J. Org. Chem., 2006, 71, 8071.
28 L. Wang, S. Feng, L. An, G. Gu and Z. Guo, J. Org. Chem., 2015, 80, 10060.

29 S. Hotha and S. Kashyap, J. Am. Chem. Soc., 2006, 128, 9620.

30 S. R. Vidadala and S. Hotha, Chem. Commun., 2009, 2505.

31 G. Sureshkumar and S. Hotha, Tetrahedron Lett., 2007, 48, 6564.

32 A. K. Kayastha and S. Hotha, Chem. Commun., 2012, 48, 7161.

33 S. A. Thadke, B. Mishra and S. Hotha, Org. Lett., 2013, 15, 2466.

34 S. A. Thadke, B. Mishra and S. Hotha, J. Org. Chem., 2014, 79, 7358.

35 B. Mishra, M. Neralkar and S. Hotha, Angew. Chem., Int. Ed., 2016, 55, 7786.

36 M. Islam, G. Gayatri and S. Hotha, J. Org. Chem., 2015, 80, 7937.

37 D. P. Nair, M. Podgorski, S. Chatani, T. Gong, W. Xi, C. O. Fenoli and C. N. Bowman, Chem. Mater., 2014, 26, 724.

38 C. E. Hoyle and C. N. Bowman, Angew. Chem., Int. Ed., 2010, 49, 1540.

39 B. H. Northrop and R. N. Coffey, J. Am. Chem. Soc., 2012, 134, 13804.

40 A. B. Lowe, Polym. Chem., 2014, 5, 4820.

41 P. Finch, G. M. Iskander and A. H. Siriwardena, Carbohydr. Res., 1991, 210, 319.

42 O. Kanie, Y. Ito and T. Ogawa, J. Am. Chem. Soc., 1994, 116, 12073.

43 C. V. S. Ramamurty, P. Ganney, C. S. Rao and B. Fraser-Reid, J. Org. Chem., 2011, 76, 2245.

44 M. Joe, Y. Bai, R. C. Nacario and T. L. Lowary, J. Am. Chem. Soc., 2007, 129, 9885; A. Ishiwata and Y. Ito, J. Am. Chem. Soc., 2011, 133, 2275.

45 G. J. S. Lohman and P. H. Seeberger, J. Org. Chem., 2004, 69, 4081.

46 See the ESI. $\dagger$ 